Article (refereed) - postprint

Pottinger, Tom G.; Matthiessen, Peter. 2016. Disruption of the stress response in wastewater treatment works effluent-exposed three-spined sticklebacks persists after translocation to an unpolluted environment. Ecotoxicology, 25 (3). 538-547. 10.1007/s10646-016-1612-3

(c) Springer Science+Business Media New York 2016

This version available http://nora.nerc.ac.uk/511265/

NERC has developed NORA to enable users to access research outputs wholly or partially funded by NERC. Copyright and other rights for material on this site are retained by the rights owners. Users should read the terms and conditions of use of this material at

http://nora.nerc.ac.uk/policies.html\#access

This document is the author's final manuscript version of the journal article, incorporating any revisions agreed during the peer review process. There may be differences between this and the publisher's version. You are advised to consult the publisher's version if you wish to cite from this article.

The final publication is available at Springer via http://dx.doi.org/10.1007/s10646-016-1612-3

Contact CEH NORA team at noraceh@ceh.ac.uk

The NERC and CEH trademarks and logos ('the Trademarks') are registered trademarks of NERC in the UK and other countries, and may not be used without the prior written consent of the Trademark owner. 


\section{Disruption of the stress response in wastewater treatment works effluent- exposed three-spined sticklebacks persists after translocation to an unpolluted environment}

Tom G. Pottinger* and Peter Matthiessen ${ }^{1}$

Centre for Ecology \& Hydrology, Lancaster Environment Centre, Library Avenue, Bailrigg, Lancaster LA1 4AP, U.K.

(1) Present address: Dolfan Barn, Beulah, Llanwrtyd Wells, Powys LD5 4UE, U.K.

*Corresponding author: T. G. Pottinger; Telephone: 441524 595854. E-mail: tgp@ceh.ac.uk

\section{Acknowledgements}

This study was funded by the U.K. Department for Environment, Food and Rural Affairs (Defra, contract CB0472) and the U.K. Natural Environment Research Council (NERC). The authors thank Mr J. Ben James (CEH Lancaster) for assistance with field sampling and Dr Richard J. Williams (CEH Wallingford) for calculating the effluent concentrations at each sample site. 


\section{Abstract}

The hypothalamic-pituitary-adrenal/interrenal (HPA/I) axis plays a key role in responding to biotic and abiotic challenges in all vertebrates. Recent studies have shown that the apical response of the HPI axis to stressors in three-spined sticklebacks varies in proportion to the concentration of wastewater treatment works (WWTW) effluent to which the fish are exposed. This study was conducted to determine whether between-site variation in stress responsiveness among WWTW effluent-exposed sticklebacks is persistent or reversible. Sticklebacks from eight sites in north-west England affected by WWTW effluent and exhibiting between-population variation in HPI axis reactivity, were moved to a clean-water aquarium environment. After five months in the contaminant-free environment the responsiveness of these fish to a standardised stressor was determined, by measuring the rate of stress-induced cortisol release across the gills, and compared with the responses of fish newly sampled from the eight original capture sites. Inter-site differences in the reactivity of the HPI axis, proportional to the effluent concentration at each site, persisted among the translocated female sticklebacks for at least 5 months. In male fish however, the direct relationship between stress responsiveness and site-specific effluent was not evident 5 months post-translocation. These results support previous observations that the HPA/I axis, a non-reproductive endocrine system, is vulnerable to modulation by anthropogenic factors in fish and show for the first time that, in female fish at least, this modulation is not transient. The mechanisms underlying these observations, and the implications for the fitness and resilience of affected populations, requires investigation.

\section{Keywords}

sewage, municipal wastewater, stress response, cortisol 


\section{Introduction}

There is worldwide concern regarding the effects of chemicals within the environment on wildlife and in particular those that cause adverse effects via interference with the normal function of endocrine-dependent processes (Trasande et al. 2015; Zoeller et al. 2012). Biota within the aquatic ecosystem are particularly vulnerable to chemical exposure given the range and quantity of anthropogenic contaminants introduced into watercourses, both deliberately and inadvertently (Henze and Comeau 2008; Marcogliese et al. 2015). Chemicals enter the aquatic environment via many routes but the discharges from wastewater treatment works (WWTW) constitute a widespread source of complex mixtures of natural and anthropogenic chemicals (Brooks et al. 2006). Effluents from WWTWs can comprise a significant proportion of the total flow in receiving waters (Keller et al. 2014) and therefore constitute a potentially substantial challenge to exposed organisms. Most research effort that addresses chemical interference with the function of endocrinedependent processes in aquatic, and terrestrial, vertebrates has focused upon chemicals with adverse effects on the function of the endocrine reproductive axis (Bergman et al. 2013; Mills and Chichester 2005). Much less attention has been directed towards contaminant-related modulation of non-reproductive endocrine processes in aquatic or terrestrial vertebrates. This observation applies in particular to the hypothalamic-pituitaryadrenal/interrenal axis (HPA/I axis; Bergman et al. 2013; Hinson and Raven, 2006). The HPA/I axis is part of a suite of adaptive responses in all vertebrates that plays a key role in responding to biotic and abiotic challenges and whose functional integrity is of great importance to the individual (Wingfield, 2013). In teleost fish, the HPI axis constitutes a neuroendocrine cascade which is activated by perception of a stressor, triggering the 
release of corticotropin-releasing hormone $(\mathrm{CRH})$ from the hypothalamus, which stimulates the release of adrenocorticotropic hormone (ACTH) by the pituitary and in turn initiates the synthesis and release of corticosteroids by the interrenal tissue (Barton, 2002). The magnitude of the apical response of the HPI axis, the release of cortisol from the interrenal tissue, is taken as a measure of the severity of the stressor. Cortisol itself has wide-ranging effects on growth, reproduction and the immune system which are believed to be adaptive in the short-term but may be harmful under conditions of prolonged stress (Sapolsky et al., 2000).

Recent studies have indicated that the magnitude of the apical HPI axis response of threespined sticklebacks (Gasterosteus aculeatus L.) to a standardised stressor, determined as the whole-body accumulation, or release to water, of cortisol, varies in proportion to the concentration of wastewater treatment works (WWTWs) effluent at the site at which the sticklebacks are resident (Pottinger et al. 2013; T. G. Pottinger, R. J. Williams and P. Matthiessen, unpublished). These findings strongly suggest that one or more regulatory sites within the HPI axis may be vulnerable to interference by factors associated with WWTW effluent. Several studies have shown that metals (e.g. Gagnon et al. 2006; Lacroix and Hontela 2004; Miller and Hontela 2011; Sandhu et al. 2014) and organic contaminants (e.g. Aluru and Vijayan 2006; Aluru et al. 2005; Bisson and Hontela 2002) affect the function of the stress axis in fish. However, although the effects of short-term exposure to wastewater have been investigated in fish (Ings et al. 2011) the mechanistic basis of effects on the stress axis associated with life-long exposure to WWTW effluent have not. As a next step to addressing this uncertainty we conducted the present study to determine whether between-site variation in stress responsiveness among three-spined sticklebacks with 
lifelong exposure to WWTW effluent is persistent or reversible. Resolving this question will inform subsequent investigations into the nature and functional significance of effluentassociated modification of the stress axis in fish.

To address this objective a translocation experiment was conducted in which three-spined sticklebacks from eight sites contaminated by WWTW effluent were moved to a clean-water aquarium environment. After five months in this contaminant-free environment the responsiveness of the translocated fish to a standardised capture / confinement stressor was determined and compared with fish sampled from the eight original capture sites and tested for stress responsiveness at the time of capture. This allowed discrimination between reversible short-term effects of exposure to effluent and persistent alterations in the functioning of the stress axis.

\section{Materials and methods}

\section{Selection of sample sites}

Eight sites downstream of wastewater treatment works (WWTWs) in north-west England were selected (Table 1) for this study. The distances between the WWTW discharge and the sample site varied between $100 \mathrm{~m}$ (Woolton, Huyton) and $2500 \mathrm{~m}$ (Blackburn). The effluent concentrations at each sample site were estimated using the Low Flows 2000 Water Quality eXtension model (LF2000-WQX) which combines hydrological models with water-quality models to make predictions on the concentration of a given chemical originating from a 
point source (Williams et al. 2009). The percentage effluent was estimated as the concentration modelled for a conservative chemical discharged from all WWTWs in the river system at a fixed concentration of $100 \mathrm{ng} / \mathrm{l}$ (Pottinger et al., 2013). The magnitude of the apical response of the stress axis to a standardised stressor had been characterised in three-spined sticklebacks (Gasterosteus aculeatus L.) resident at these sites during previous studies (Pottinger et al. 2013; T. G. Pottinger, R. J. Williams and P. Matthiessen, unpublished) and found to be proportional to the percentage of WWTW-derived effluent at each sampling site. We were therefore confident that fish from these locations would provide a suitable range of variation in stress responsiveness for the present study.

\section{Translocated aquarium populations}

During October 2013 approximately sixty fish were collected from each of the selected sites. Fish were captured using a metal-framed $45 \mathrm{~cm}$ D-profile handnet, temporarily retained in buckets containing river water and then transferred to the CEH Lancaster aquarium in 20 litre polypropylene containers. Here the fish were placed in 30 I glass aquaria, each supplied with a constant flow $(800 \mathrm{ml} / \mathrm{min})$ of untreated water from a nearby tarn with no history of sewage or any other direct discharge (Blea Tarn Reservoir, Hazelrigg, Lancaster; NGR SD 493 585). Fish from each sample site were randomly distributed between two aquaria (approx. 30 fish/tank). The fish were maintained under a short daylength (7.5h : 16.5h: L:D) and were fed bloodworm three times weekly. Water temperature during the period of the study (October 2013 - March 2014) ranged between $9.9^{\circ} \mathrm{C}$ and $13.8^{\circ} \mathrm{C}\left(11.4 \pm 0.01^{\circ} \mathrm{C}\right.$, mean $\left.\pm \mathrm{SE}\right)$. Mortalities throughout the holding period were low $(0-6 \%)$ for all populations with the exception of the fish captured from Netherley Brook (Woolton WWTW) in which total losses 
during the holding period were $30 \%$.

\section{Assessment of stress responsiveness in the translocated aquarium populations}

Because of the small size of the target species and the remote locations of the sampling sites the acquisition and processing of blood samples was impractical. Instead, the magnitude of the stress response was measured indirectly via the release of cortisol across the gill epithelium to the surrounding water (Scott and Ellis 2007) the rate of which varies in proportion with blood cortisol concentrations (Félix et al. 2013; Friesen et al. 2012; Gabor and Contreras 2012; Wong et al. 2008). During March 2014 five fish were transferred by handnet from a holding tank to a bucket containing 5 litres of water in which they remained for 30 mins before being transferred to individual Nalgene tubs $(150 \mathrm{ml}, 6.5 \mathrm{~cm}$ diameter, with screw-fit lids) containing $100 \mathrm{ml}$ of artificial freshwater (deionised water containing $0.33 \mathrm{~g} / \mathrm{l}$ aquarium grade sea salt; Klüttgen et al. 1994). During exposure to the combined capture, handling and confinement stressor blood cortisol concentrations in three-spined sticklebacks plateau within 30 mins and remain stable for up to 60 minutes thereafter (T. G. Pottinger, unpublished data). After a further 30 minutes these fish were transferred to beakers containing an overdose of sedative (2-phenoxyethanol, 1:1000) and when unresponsive to a tail pinch were placed individually in labelled $12 \mathrm{ml}$ polypropylene centrifuge tubes and snap-frozen by transfer to a dry shipper containing liquid $\mathrm{N}_{2}$ (TaylorWharton CX 100). This procedure was repeated for all sixteen holding tanks (each of eight sites in duplicate). A total of 10 stressed fish was sampled in this way from each site population. The tubs containing the water samples were transferred to a freezer $\left(-20^{\circ} \mathrm{C}\right)$ to await extraction and fish samples were also frozen to await dissection. In due course each 
fish was thawed and weighed to the nearest mg. Total length was recorded to the nearest $\mathrm{mm}$, and the sex of each fish was determined by macroscopic examination of the gonads after making a ventral incision.

\section{Field-testing of stress responsiveness in wild-caught fish}

During March 2014 the eight sites from which the translocated populations were obtained in October 2013 were revisited to obtain individuals for comparison with the aquarium-held translocated sticklebacks. At each site ten fish were captured and retained in a bucket containing river water for a period of up to 45 minutes before being transferred to individual capped Nalgene tubs $(150 \mathrm{ml}, 6.5 \mathrm{~cm}$ diameter) containing $100 \mathrm{ml}$ of artificial freshwater in which they were confined for 30 minutes. As noted above, blood cortisol concentrations in three-spined sticklebacks plateau within 30 mins and remain stable for up to 60 minutes thereafter. Artificial FW, rather than the river water at each site, was used for the collection of water-borne cortisol to minimise the inclusion of suspended solids likely to interfere with the subsequent extraction procedure, and to allow the collecting vessels to be prepared in advance. The fish were then killed by transfer to a bucket containing an overdose of sedative (2-phenoxyethanol, 1:1000) and when unresponsive to a tail pinch were transferred to individually labelled $12 \mathrm{ml}$ capped polypropylene test tubes which were placed into a small dry shipper (Taylor-Wharton CX 100) containing liquid nitrogen. The fish samples were subsequently transferred to a larger dry-shipper (Taylor-Wharton CX500) for transfer back to $\mathrm{CEH}$ Lancaster where samples were stored at $-80^{\circ} \mathrm{c}$ prior to processing as described above. Water samples were held on ice in coolboxes until return to CEH Lancaster where they were transferred to a freezer $\left(-20^{\circ} \mathrm{C}\right)$ for storage. 


\section{Extraction of water samples}

Water samples within which single sticklebacks had been held post-capture for a period of 30 mins were thawed at room temperature. Each sample was pumped (Watson Marlow $202 \mathrm{~S}$ multi-channel peristaltic pump, 10-20 ml/min, 12 active channels, $2.79 \mathrm{~mm}$ i.d. silicone tubing) through an inline $0.45 \mu \mathrm{m}$ pre-filter (Pall Gellman Acrocap, Pall Life Sciences) and a Sep-Pak C18 cartridge (Waters Ltd). Sep-Pak cartridges were cleaned and conditioned by flushing with $5 \mathrm{ml}$ of ethyl acetate, followed by $5 \mathrm{ml}$ methanol, followed by $5 \mathrm{ml}$ deionised water using a vacuum manifold. The cartridges were not allowed to dry out between conditioning and receiving the water sample. One blank (100 $\mathrm{ml}$ artificial freshwater only) and one recovery standard (100 $\mathrm{ml}$ artificial freshwater containing a $100 \mu \mathrm{l}$ aliquot of a solution of cortisol in ethanol, $5 \mathrm{ng} / \mathrm{ml}$ ) were included with each batch of ten water samples $(100 \mathrm{ml})$. No spurious signal was detected in any of the blanks and recovery of added cortisol was consistently $>85 \%$. After extraction, cortisol was immediately eluted from the Sep-Pak cartridge with $2.5 \mathrm{ml}$ ethyl acetate in a vacuum manifold. The eluate was dried in a heating block under a stream of air at $40^{\circ} \mathrm{C}$ and redissolved in $350 \mu$ ethyl acetate. A $150 \mu \mathrm{l}$ aliquot of the reconstituted extract was taken for assay.

\section{Cortisol radioimmunoassay}

The concentration of cortisol in water samples within which individual fish had been confined was determined by radioimmunoassay (Pottinger and Carrick 2001). Two minor adjustments were made to the published method. The antibody used in this study was IgG- 
F-2 rabbit anti-cortisol (IgG Corp; Nashville, TN, USA) and tracer $\left(\left[1,2,6,7-{ }^{3} \mathrm{H}\right]\right.$-cortisol, 2.59 $\mathrm{TBq} / \mathrm{mmol}$; Perkin-Elmer, U.K.) was added in a $25 \mu \mathrm{l}$ aliquot of buffer at the same time as the antibody was dispensed.

\section{Statistical analysis}

The relationship between effluent concentration and the cortisol response to confinement, and between effluent concentration and somatic data, was investigated using linear regression (Sigmaplot v. 12; Systat Software, Inc.). The relationship between stress-induced release of cortisol to water among fish held in the aquarium for 5 months and fish from the same sites tested immediately after capture from the river was investigated using Deming regression (Sigmaplot). Differences in somatic characteristics and in the cortisol response to confinement between wild-caught and aquarium-held fish, and between sexes, were assessed on log-transformed data+1 using two-way ANOVA (Sigmaplot). The coefficient of condition ( $\mathrm{K}$, Fulton's condition index) was calculated as $\mathrm{K}=(100 *$ weight $) /\left(\right.$ length $\left.{ }^{3}\right)$ (Bolger and Connolly 1989).

\section{Results}

\section{Cortisol release rates in relation to effluent concentration}

The stress-induced rate of release of cortisol to water (WC) was significantly higher among the translocated fish than wild-caught fish $(F(1,156)=18.3, p<0.001$; Table 2$)$ and the WC 
release rates were overall higher in females than males $(F(1,156)=31.6, p<0.001$; Table 2$)$. There was no significant interaction between these factors $(F(1,156)=3.1, p=0.08)$. A significant positive relationship was evident between the stress-induced cortisol release rate and the estimated effluent concentration at the same site for wild-caught female sticklebacks subjected to a confinement stressor immediately after capture (Fig. 1a: $r^{2}=$ 0.13, $p=0.02, \mathrm{n}=43$ ). A similar significant trend was apparent for male fish (Fig. 1c: $r^{2}=$ $0.24, p=0.002, \mathrm{n}=37)$. When the translocated aquarium-held fish were tested for stressresponsiveness in March 2014 the rate of release of cortisol to water by female fish was positively related to the effluent concentration at their sites of origin (Fig. 1b: $r^{2}=0.16, p=$ $0.006, n=46$ ) but this relationship was not evident among the aquarium-translocated males (Fig. 1d: $r^{2}=0.00, p=0.89, \mathrm{n}=34$ ).

In the absence of a clear relationship between stress-responsiveness and site-specific effluent concentration among the male fish we assessed whether similarities between the responsiveness of the river-caught and aquarium-reared fish from the same site were evident, irrespective of the effluent concentration at the original capture site. Because measurement error was associated with the data points on both axes of these plots, Deming regressions were conducted (Fig. 2). The Deming regression model coefficients indicated that there were no proportional differences between the two groups, for either male fish or female fish. For both males and females, there was no proportional bias between the rivercaught and aquarium-reared groups with the confidence interval $(\mathrm{Cl})$ for the slope coefficient ( $0.07-1.13$ and $0.32-1.52$ respectively) including 1 , indicating that the hypothesis that the slopes equal 1 was not rejected. A similar outcome was obtained when the anomalous value (Altrincham, aquarium-reared males) was included. For males, there 
was in addition no systematic difference between the two data sets with the confidence interval for the intercept (-197 - 1028) including 0 therefore accepting the hypothesis that the intercept was 0. For the female fish, however, the $\mathrm{Cl}$ for the intercept (402 - 2022) did not include 0 , an outcome consistent with the higher cortisol release levels shown for aquarium-reared female fish in Table 2.

\section{Cortisol release rates in relation to fish size}

Among the wild-caught fish a significant negative relationship was apparent between body mass and release of cortisol to water during confinement for both sexes (Fig. 3a: $r^{2}=0.26, P$ $<0.001, \mathrm{n}=43$, Fig. 3c: $r^{2}=0.57, P<0.001, \mathrm{n}=37$ ) but this trend was absent in the fish sampled after five months in the aquarium environment (Fig. $3 \mathrm{~b}, \mathrm{~d}: r^{2}<0.1, p>0.1, \mathrm{n}=46$, 34).

\section{Fish size in relation to effluent concentration}

The translocated aquarium-reared fish were heavier overall than the wild-caught individuals $(F(1,156)=9.1, p=0.003 ;$ Table 2$)$ and females were larger than males $(F(1,156)=4.4, p=$ 0.04; Table 2). There was no interaction between these factors $(F(1,156)=0.8, p=0.4)$. Length varied significantly in a similar fashion (Table 2). However, the coefficient of condition did not vary significantly with either sex or treatment. For wild-caught fish captured in March 2014 the body mass of both female and male sticklebacks was significantly and inversely related to the estimated concentration of effluent at the site of 
capture (Fig. 4a: $r^{2}=0.19, p=0.003, \mathrm{n}=43$; Fig. 4c: $r^{2}=0.14, p=0.02, \mathrm{n}=37$ ) but for the translocated fish no significant relationship between body mass and the effluent concentration at their site of origin was apparent when the fish were sampled in March 2014 (Fig. 4b,d: $r^{2}<0.1, p>0.1, \mathrm{n}=46,34$ ). Similar trends were evident for the total length of fish of both sexes (data not shown, female wild-caught: $r^{2}=0.29, p<0.001, \mathrm{n}=43$; male wild-caught: $r^{2}=0.19, p=0.007, \mathrm{n}=37$; female and male aquarium-reared: $r^{2}=0.0, p>0.3$, $n=46,34)$.

\section{Discussion}

\section{Site-specific trends in stress responsiveness are retained in female sticklebacks after} translocation to an uncontaminated environment

Site-dependent trends in the stress-induced rate of release of cortisol to water (WC) were evident in three-spined sticklebacks of both sexes sampled from locations downstream of WWTW effluent discharges. Overall, WC release rates, which provide a surrogate for blood cortisol concentrations (Félix et al. 2013; Friesen et al. 2012; Gabor and Contreras 2012; Wong et al. 2008), were directly proportional to the estimated concentration of WWTW effluent at these sites. Female sticklebacks translocated from the same sites five months previously and subsequently held in pristine aquarium conditions continued to exhibit the same site-related trends in WC release rates as their more recently wild-caught counterparts. This relationship was not evident among male fish. Although stress responsiveness among the wild-caught males was positively related to the concentration of 
effluent at their site of capture, the same relationship was not evident among the translocated males reared under aquarium conditions for 5 months. Counter-intuitively, there remained a positive and statistically significant relationship between the magnitude of stress-induced WC concentrations in the wild-caught males and in the translocated aquarium-reared male fish. These results suggest that in female fish at least, the alterations in stress axis function that are responsible for variation in stress-induced WC in sticklebacks are irreversible in the short- to medium-term, and do not require ongoing exposure to the home environment in order to be sustained.

Variation in the estimated effluent concentration accounted for up to $25 \%$ of the betweensite variation in WC. This is a smaller proportion than reported in a related study across a greater number of sites in which up to $45 \%$ of the variation in WC was explained by effluent concentration (T. G. Pottinger and P. Matthiessen, unpublished). The lower proportion of variation in stress-induced WC explained by the effluent estimates in the present study may be a consequence of the generalisations that are unavoidably inherent in the effluent concentration estimates (Johnson et al. 2008), together with the possibility that effluent concentration itself does not precisely reflect between-site differences in the primary determinant(s) of variation in stress responsiveness, and that additional independent or interacting factors of which we are unaware may also be important. One such factor is the susceptibility of the HPI axis in male fish to modulation by endogenous androgens during the reproductive cycle (Pottinger et al. 1996), which, given the time of year at which sampling was conducted, probably accounts for the overall lower concentrations of WC released by males at each site compared with females from the same sites, and may have contributed to some degree to the loss of overt proportionality with the effluent 
concentration. Nonetheless, the association between stress axis reactivity in translocated female fish and effluent concentration at their sites of origin does implicate effluent exposure as a contributory factor in determining these differences. Three mechanisms may be proposed to account for the persistence of site-dependent differences in WC release rates in females: (1) changes in HPI axis function that in themselves are not adaptive but are a consequence of effluent-driven adaptive processes which have led to genetic differences between populations (Bélanger-Deschênes et al. 2013; Lind and Grahn 2011; Williams and Oleksiak 2008) (2) epigenetic effects on regulatory elements within the stress axis (Hala et al. 2014; Vandegehuchte and Janssen 2014; Zhang and Ho 2011) arising from exposure to chemicals associated with WWTW effluent; or (3) chemical intervention at a key early developmental stage (Gore 2008; Hamlin and Guillette 2011) with consequences for HPI axis function in the adult. At present, we have insufficient data to speculate further as to which of these alternative explanations best accounts for the results of the study, or whether additional explanations must be sought.

\section{Effluent-related variation in fish size is eliminated by translocation}

For both male and female wild-caught sticklebacks, size (body weight and total length) was inversely related to the estimated effluent concentration at the sites of capture. This finding differs from previous studies which have reported a positive trend between WWTW effluent concentration and the size of resident fish (Pottinger et al. 2013; Tetreault et al. 2012) but is consistent with the results of a study in which the growth of sticklebacks downstream of a WWTW was improved following remediation of the effluent (Pottinger et al. 2011). WWTW 
effluent contains nutrients likely to improve productivity of the downstream aquatic ecosystem and WWTW effluent discharges also tend to raise the water temperature in receiving waters (Brooks et al. 2006; Gücker et al. 2006), both of which are factors that have a positive effect on the growth of fish (Beardsley and Britton, 2012; Graham and Harrod 2009). However, WWTW effluent also contains chemicals with the potential to exert a negative effect on the growth of fish via direct effects on physiological or endocrine processes, or because the fish need to divert resources to coping with a toxicological challenge (Forbes and Calow 1998). The interplay between these growth-promoting and growth-suppressing factors may result in different outcomes across different contexts. Whatever the cause of the between-site differences in size that were evident among the wild-caught fish, the absence of size differences among the translocated fish suggest that the innate scope for growth of the fish was not affected by prior exposure to effluent and that the differences in the size of fish among sites in the March 2014 wild-caught sample arose due to proximate factors. The absence of between-site differences in fish size among the translocated fish eliminated the significant inverse relationship between body mass and stress-induced water cortisol release that was apparent among the wild-caught fish.

\section{The absolute magnitude of the stress response is altered by translocation}

Overall the WC response to confinement was greater among the aquarium-reared fish than the wild-caught fish. Water temperature can affect the magnitude of the cortisol stress response in fish (Pottinger et al. 1999) but here the average river temperatures at the time of capture in March $2014\left(10.8^{\circ} \mathrm{C}\right)$ were close to the average water temperature in the aquarium at the same time $\left(10.9^{\circ} \mathrm{C}\right)$. It is of course possible that stress responsiveness of the 
fish at the time of testing was influenced by the temperature regime experienced across the preceding weeks or months. The annual temperature range seen in the field sites (e.g. Sinderland Brook: $2^{\circ} \mathrm{C}-20^{\circ} \mathrm{C}$ : data taken from the U.K. Environment Agency's Water Information Management System) was greater than that experienced by the translocated fish (aquarium water temperature range $10^{\circ} \mathrm{C}-14^{\circ} \mathrm{C}$ ). Given the array of variables that differed between the translocated and river-resident fish it is impossible to identify the specific cause of these differences.

\section{Conclusion}

In female three-spined sticklebacks the relationship between HPI axis reactivity and the effluent concentration at their sites of origin, remained intact after translocation and prolonged rearing in an unpolluted environment. In male fish this relationship did not persist after translocation: although a significant relationship between stress-induced cortisol release rates in wild-caught and translocated males was apparent, release rates in the translocated fish were not directly associated with site-specific effluent concentration. These findings suggest that the variation in stress response seen across sites receiving WWTW effluent is, in female fish at least, a robust trait that reflects either the indirect consequences of local adaptations at a genetic level, persistent effects on the stress axis arising from contaminant exposure during early development, or is the result of epigenetic mechanisms. The outcomes of this study provide more evidence that non-reproductive endocrine systems in fish are vulnerable to modulation by anthropogenic factors but raise questions regarding the sex-dependent specificity of the effect. Further work, including investigation of the trans-generational persistence of these effects, laboratory-based 
effluent exposure studies and targeted transcriptome analysis, is needed to identify the underlying mechanism and critically, to determine the implications for the fish in terms of their overall fitness and resilience to further challenges.

\section{Conflict of Interest}

The authors declare that they have no conflict of interest.

\section{Ethical approval}

The confinement stress procedure to which the aquarium-held and wild-caught fish were subjected was approved by the Lancaster University Animal Welfare and Ethical Review Body and was conducted under UK Home Office licence.

\section{REFERENCES}

Aluru N, Vijayan MM. (2006) Aryl hydrocarbon receptor activation impairs cortisol response to stress in rainbow trout by disrupting the rate-limiting steps in steroidogenesis. Endocrinology 147, 1895-1903.

Aluru N, Renaud R, Leatherland JF, Vijayan MM (2005) Ah receptor-mediated impairment of interrenal steroidogenesis involves StAR protein and P450scc gene attenuation in rainbow trout. Toxicol Sci 84:260-269. 
Barton BA, (2002) Stress in fishes: A diversity of responses with particular reference to changes in circulating corticosteroids. Integr Comp Biol 42: 517-525.

Beardsley H, Britton JR (2012) Contribution of temperature and nutrient loading to growth rate variation of three cyprinid fishes in a lowland river. Aquat Ecol 46:143-152.

Bélanger-Deschênes S, Couture SP, Campbell PGC, Bernatchez L (2013) Evolutionary change driven by metal exposure as revealed by coding SNP genome scan in wild yellow perch (Perca flavescens). Ecotoxicology 22:938-957.

Bergman Å, Heindel JJ, Jobling S, Kidd KA, Zoeller RT, eds. State of the Science of Endocrine Disrupting Chemicals 2012; United Nations Environment Programme and World Health Organization: Geneva, 2013. Available: http://www.who.int/ceh/publications/endocrine/en/ [accessed 6 July 2015]

Bisson M, Hontela A (2002) Cytotoxic and endocrine-disrupting potential of atrazine, diazinon, endosulfan, and mancozeb in adrenocortical steroidogenic cells of rainbow trout exposed in vitro. Toxicol Appl Pharmacol 180:110-117.

Bolger T, Connolly PL (1989) The selection of suitable indices for the measurement and analysis of fish condition. J Fish Biol 34:171-182.

Brooks BW, Riley TM, Taylor RD (2006) Water quality of effluent-dominated ecosystems: 
ecotoxicological, hydrological, and management considerations. Hydrobiologia 556:365-379.

Félix AS, Faustino Al, Cabral EM, Oliveira RF (2013) Noninvasive measurement of steroid hormones in zebrafish holding-water. Zebrafish 10:110-115.

Forbes VE, Calow P (1998) Costs of living with contaminants: Implications for assessing lowlevel exposures. Comment Toxicol 6:255-270.

Friesen CN, Chapman LJ, Aubin-Horth N (2012) Holding water steroid hormones in the African cichlid fish Pseudocrenilabrus multicolor victoriae. Gen Comp Endocrinol 179:400-405.

Gabor CR, Contreras A (2012) Measuring water-borne cortisol in Poecilia latipinna: is the process stressful, can stress be minimized and is cortisol correlated with sex steroid release rates? J Fish Biol 81:1327-1339.

Gagnon A, Jumarie C, Hontela A (2006) Effects of Cu on plasma cortisol and cortisol secretion by adrenocortical cells of rainbow trout (Oncorhynchus mykiss). Aquat Toxicol 78:59-65.

Gore AC (2008) Developmental programming and endocrine disruptor effects on reproductive neuroendocrine systems. Front Neuroendocrinol 29:358-374. 
Graham CT, Harrod C (2009) Implications of climate change for the fishes of the British Isles. J Fish Biol 74:1143-205.

Gücker B, Brauns M, Pusch MT (2006) Effects of wastewater treatment plant discharge on ecosystem structure and function of lowland streams. J N Am Benthol Soc 25:31329.

Hala D, Huggett DB, Burggren WW (2014) Environmental stressors and the epigenome. Drug Discov Today 12:e3-e8.

Hamlin HJ, Guillette LJ (2011) Embryos as targets of endocrine disrupting contaminants in wildlife. Birth Defects Res C 93:19-33.

Henze M, Comeau, Y (2008) Wastewater characterization. In: Biological Wastewater Treatment: Principles Modelling and Design. (Henze M, van Loosdrecht MCM, Ekama GA, Brdjanovic D, eds). London, UK:IWA Publishing, 33-52.

Hinson JP, Raven PW (2006) Effects of endocrine-disrupting chemicals on adrenal function. Best Pract Res Clin Endocrinol Metab 20:111-120.

Ings JS, Servos MR, Vijayan MM (2011) Exposure to municipal wastewater effluent impacts stress performance in rainbow trout. Aquat Toxicol 103:85-91. 
Johnson AC, Ternes T, Williams RJ, Sumpter JP (2008) Assessing the concentrations of polar organic microcontaminants from point sources in the aquatic environment: measure or model? Environ Sci Technol 42:5390-5399.

Keller VDJ, Williams RJ, Lofthouse C, Johnson AC (2014) Worldwide estimation of river concentrations of any chemical originating from sewage-treatment plants using dilution factors. Environ Toxicol Chem 33:447-452.

Klüttgen B, Dülmer U, Engels M, Ratte HT (1994) ADaM, an artificial freshwater for the culture of zooplankton. Wat Res 28:743-746.

Lacroix A, Hontela A (2004) A comparative assessment of the adrenotoxic effects of cadmium in two teleost species, rainbow trout, Oncorhynchus mykiss, and yellow perch, Perca flavescens. Aquat Toxicol 67, 13-21.

Lind EE, Grahn M (2011) Directional genetic selection by pulp mill effluent on multiple natural populations of three-spined stickleback (Gasterosteus aculeatus). Ecotoxicology 20, 503-512.

Marcogliese DJ, Blaise C, Cyr D, de Lafontaine Y, Fournier M, Gagné F, Gagnon C, Hudon C (2015) Effects of a major municipal effluent on the St. Lawrence River: A case study. AMBIO 44, 257-274. 
Miller LL, Hontela A (2011) Species-specific sensitivity to selenium-induced impairment of cortisol secretion in adrenocortical cells of rainbow trout (Oncorhynchus mykiss) and brook trout (Salvelinus fontinalis). Toxicol Appl Pharmacol 253:137-144.

Mills $\amalg$, Chichester C (2005) Review of evidence: Are endocrine-disrupting chemicals in the aquatic environment impacting fish populations? Sci Total Environ 343:1-34.

Pottinger TG, Carrick TR (2001) Stress responsiveness affects dominant-subordinate relationships in rainbow trout. Horm Behav 40:419-427.

Pottinger TG, Carrick TR, Hughes SE, Balm PHM (1996) Testosterone, 11-ketotestosterone and estradiol-17 $\beta$ modify baseline and stress-induced interrenal and corticotropic activity in trout. Gen Comp Endocrinol 104:284-295

Pottinger TG, Cook A, Jürgens MD, Rhodes G, Katsiadaki I, Balaam JL, Smith AJ, Matthiessen P (2011) Effects of sewage effluent remediation on body size, somatic RNA:DNA ratio, and markers of chemical exposure in three-spined sticklebacks. Environ Int 37:158-169.

Pottinger TG, Henrys PA, Williams RJ, Matthiessen P (2013) The stress response of threespined sticklebacks is modified in proportion to effluent exposure downstream of wastewater treatment works. Aquat Toxicol 126:382-392. 
Pottinger TG, Yeomans WE, Carrick TR (1999) Plasma cortisol and 17 $\beta$-estradiol levels in roach, Rutilus rutilus (L.), exposed to acute and chronic stress. J Fish Biol 54:525-532.

Sandhu N, McGeer JC, Vijayan MM (2014) Exposure to environmental levels of waterborne cadmium impacts corticosteroidogenic and metabolic capacities, and compromises secondary stressor performance in rainbow trout. Aquat Toxicol 146, 20-27.

Sapolsky RM, Romero LM, Munck AU (2000). How do glucocorticoids influence stress responses? Integrating permissive, suppressive, stimulatory, and preparative actions. Endocr Rev 21: 55-89.

Scott AP, Ellis T (2007) Measurement of fish steroids in water-a review. Gen Comp Endocrinol 153:392-400.

Tetreault GR, Bennett CJ, Cheng C, Servos MR, McMaster ME (2012) Reproductive and histopathological effects in wild fish inhabiting an effluent-dominated stream, Wascana Creek, SK, Canada. Aquat Toxicol 110-111:149-161.

Trasande L, Zoeller RT, Hass U, Kortenkamp A, Grandjean P, Myers JP, DiGangi J, Bellanger M, Hauser R, Legler J, Skakkebaek NE, Heindel JJ (2015) Estimating burden and disease costs of exposure to endocrine-disrupting chemicals in the European Union. J Clin Endocrinol Metab 100:1245-1255. 
Vandegehuchte MB, Janssen CR (2014) Epigenetics in an ecotoxicological context. Mutat Res - Genet Toxicol Environ Mutagen 764-765:36-45.

Williams LM, Oleksiak MF (2008) Signatures of selection in natural populations adapted to chronic pollution. BMC Evol Biol 8:282

Williams RJ, Keller VDJ, Johnson AC, Young AR, Holmes MGR, Wells C, Gross-Sorokin M, Benstead R (2009) A national risk assessment for intersex in fish arising from steroid estrogens. Environ Toxicol Chem 28:220-230.

Wingfield JC (2013) The comparative biology of environmental stress: behavioural endocrinology and variation in ability to cope with novel, changing environments. Anim Behav 85: 1127-1133.

Wong SC, Dykstra M, Campbell JM, Earley RL (2008) Measuring water-borne cortisol in convict cichlids (Amatitlania nigrofasciata): is the procedure a stressor? Behaviour $145,1283-1305$.

Zhang X, Ho SM (2011) Epigenetics meets endocrinology. Journal of Molecular Endocrinology 46, R11-R32.

Zoeller RT, Brown TR, Doan LL, Gore AC, Skakkebaek NE, Soto AM, Woodruff TJ, Vom Saal FS (2012) Endocrine-disrupting chemicals and public health protection: a statement of principles from The Endocrine Society. Endocrinology 153, 4097-4110. 


\section{Tables}

Table 1. Sites sampled to provide fish for aquarium-reared $v$. wild-caught comparison. DS downstream, US - upstream. Effluent concentrations were calculated with the Low Flows 2000 Water Quality eXtension model (LF2000-WQX; Williams et al., 2009) using flow data for the period 1960-1991. NGR - National grid reference, U.K. Ordnance Survey.

\begin{tabular}{|c|c|c|c|c|}
\hline $\begin{array}{l}\text { WWTW } \\
\text { name }\end{array}$ & $\begin{array}{l}\text { Discharge } \\
\text { location } \\
\text { (NGR) }\end{array}$ & $\begin{array}{c}\text { Sample site } \\
\text { location (NGR) }\end{array}$ & Receiving water & $\begin{array}{c}\text { Effluent } \\
\text { concentration (\% } \\
\text { of river flow) }\end{array}$ \\
\hline Leyland & SD 521208 & SD 517200 & River Lostock & 19 \\
\hline Blackburn & SD 605294 & SD 590282 & River Darwen DS & 30 \\
\hline Altrincham & SJ 750904 & SJ 738905 & Sinderland Brook & 31 \\
\hline Darwen & SD 690243 & SD 690246 & River Darwen US & 34 \\
\hline Huyton & SJ 452879 & SJ 452877 & Netherley Brook & 39 \\
\hline Denton & SJ 921935 & SJ 919937 & River Tame & 54 \\
\hline Woolton & SJ 450875 & SJ 448874 & Netherley Brook & 73 \\
\hline Hillhouse & SD 350056 & SD 353047 & $\begin{array}{l}\text { Maghull Hey Cop } \\
\text { Drain }\end{array}$ & 95 \\
\hline
\end{tabular}


Table 2. A summary of somatic data and WC results for the aquarium-reared population (caught October 2013 and held in the aquarium until March 2014) and wild-caught population (caught March 2014) at the time of testing in March 2014.

\begin{tabular}{ccccccc}
\hline Sex & Population & $\mathbf{n}$ & mean \pm SE & $\begin{array}{c}\text { mean } \pm \text { SE } \\
(\mathbf{m m})\end{array}$ & mean \pm SE & mean \pm SE \\
\hline \multirow{2}{*}{ female } & river & 43 & $1651 \pm 156$ & $51.0 \pm 1.6$ & $1.100 \pm 0.02$ & $1883 \pm 256$ \\
& aquarium & 46 & $1670 \pm 67$ & $53.9 \pm 0.7$ & $1.043 \pm 0.02$ & $2880 \pm 194$ \\
& river & 37 & $1246 \pm 106$ & $47.3 \pm 1.5$ & $1.073 \pm 0.02$ & $1169 \pm 161$ \\
male & aquarium & 34 & $1537 \pm 96$ & $51.9 \pm 0.8$ & $1.056 \pm 0.02$ & $1357 \pm 151$ \\
& & & & & &
\end{tabular}

${ }^{1} \mathrm{~K}$ - coefficient of condition.

${ }^{2} \mathrm{WC}$ - rate of release of cortisol to water. 


\section{Figures}

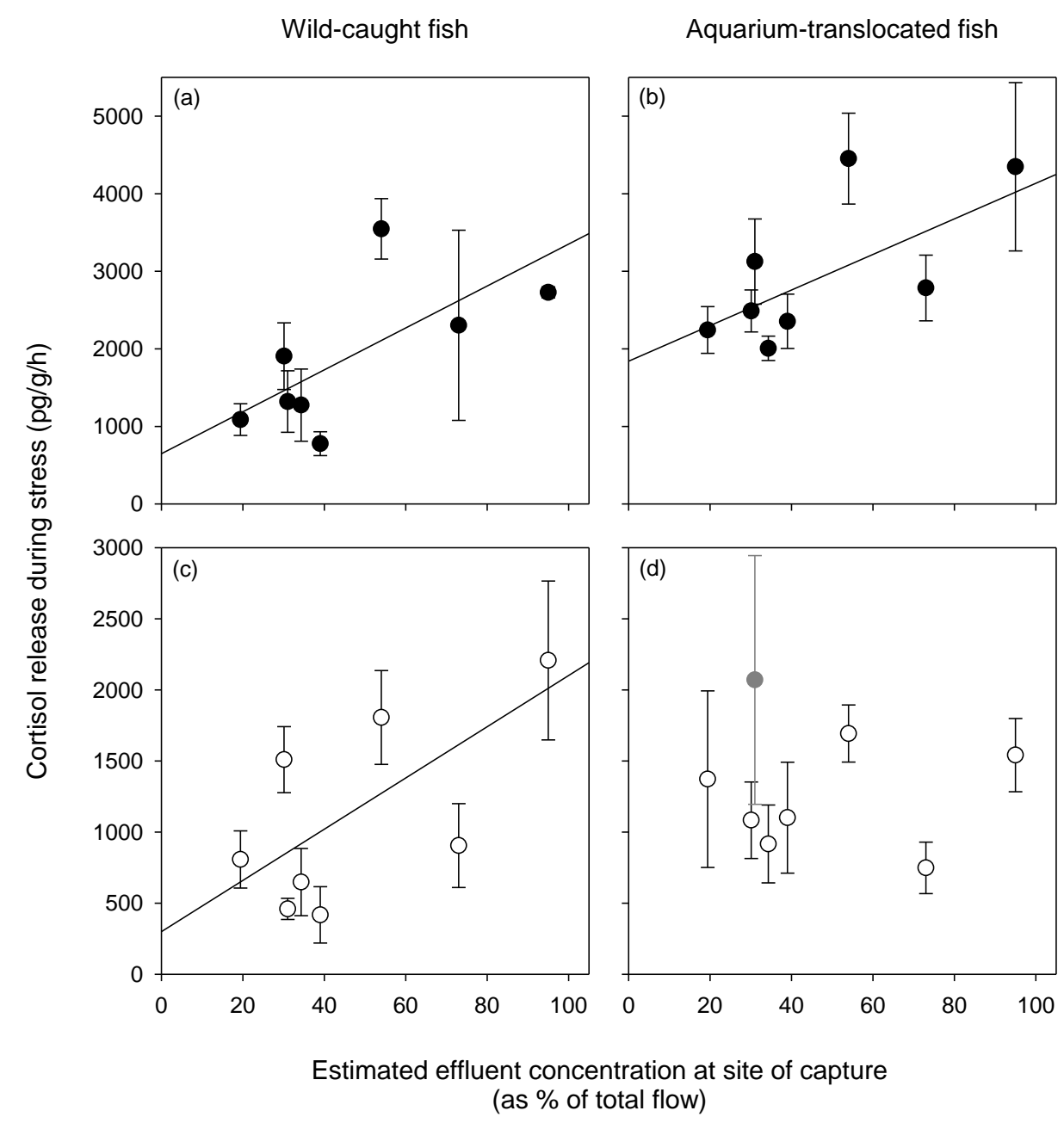

Figure 1. Mean cortisol released to water during exposure to a standardised confinement stressor by: (a) female $(\mathbf{O})$ and $(c)$ male $(O)$ sticklebacks captured and tested at the sites shown in Table 1 during March 2014; (b) female and (d) male sticklebacks captured at the sites shown in Table 1 during October 2013, transferred to the CEH aquarium, and tested during March 2014. In (d) the mean value for fish from Sinderland Brook (Altrincham WWTW) is shown in grey for comparison with Fig. $2 b$. Best-fit regression lines are shown. The regressions were conducted using the raw data, but means \pm SEM are shown for clarity, $\mathrm{n}=3-7$. Fig. 1a: $\mathrm{r} 2=0.13, \mathrm{p}=0.02, \mathrm{n}=43$; Fig. $1 \mathrm{~b}: \mathrm{r} 2=0.16, \mathrm{p}=0.006, \mathrm{n}=46$; Fig. $1 \mathrm{c}: \mathrm{r} 2=$ $0.24, p=0.002, n=37$; Fig. $1 d: r 2=0.00, p=0.89, n=34$. 


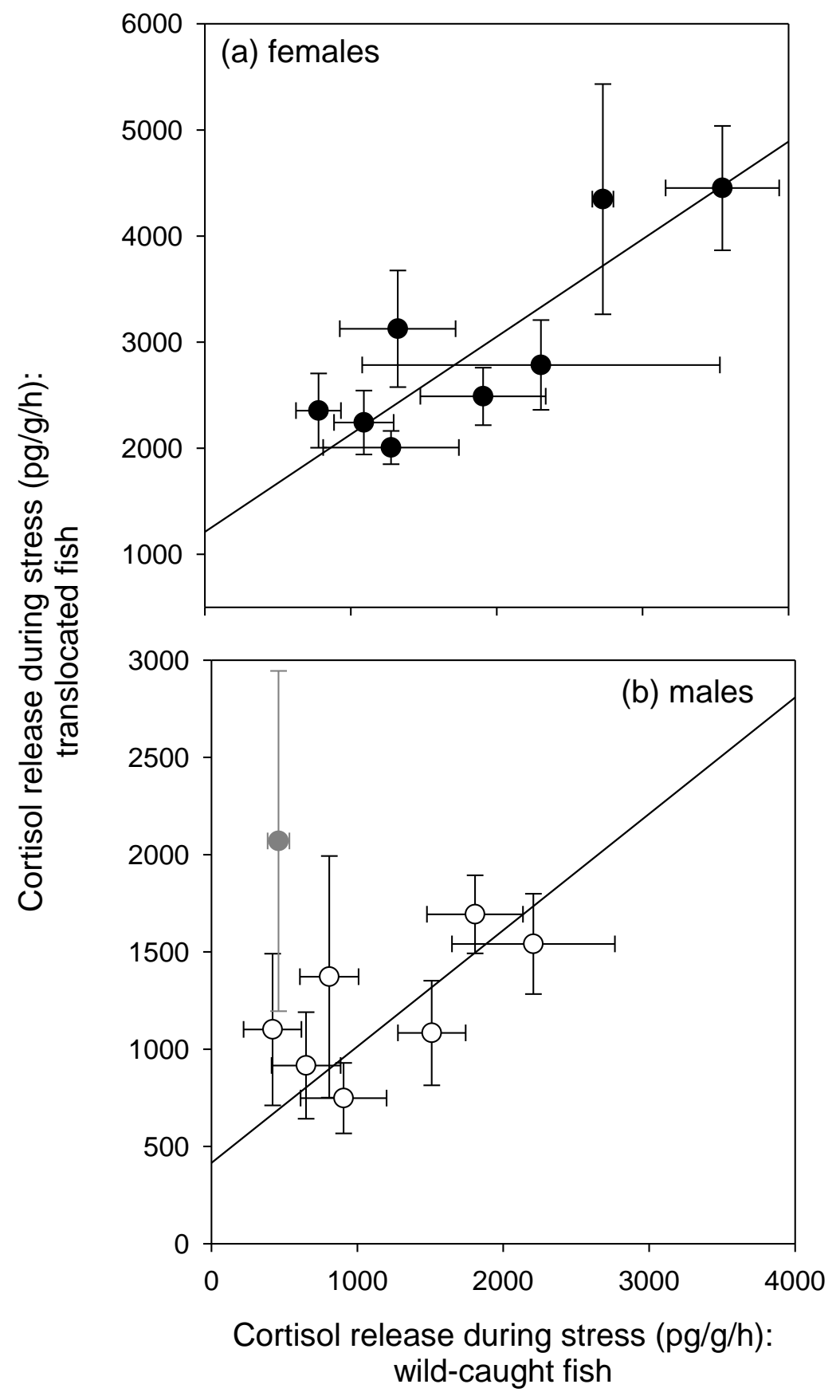

Figure 2. Scatter plots showing the relationship between stress-induced cortisol release to water in (a) female and (b) male sticklebacks captured from the wild at eight sites downstream of WWTW discharges (see Table 1) and immediately exposed to a standardised confinement stressor (wild-caught fish; $x$-axes) and sticklebacks captured the same sites in October 2013, transferred to the CEH aquarium, and tested in March 2014 (aquariumheld fish; y-axes). The mean value for male fish from Sinderland Brook (Altrincham WWTW) is shown in grey and was excluded from the regression shown. Deming regression outcomes are reported in the text. 


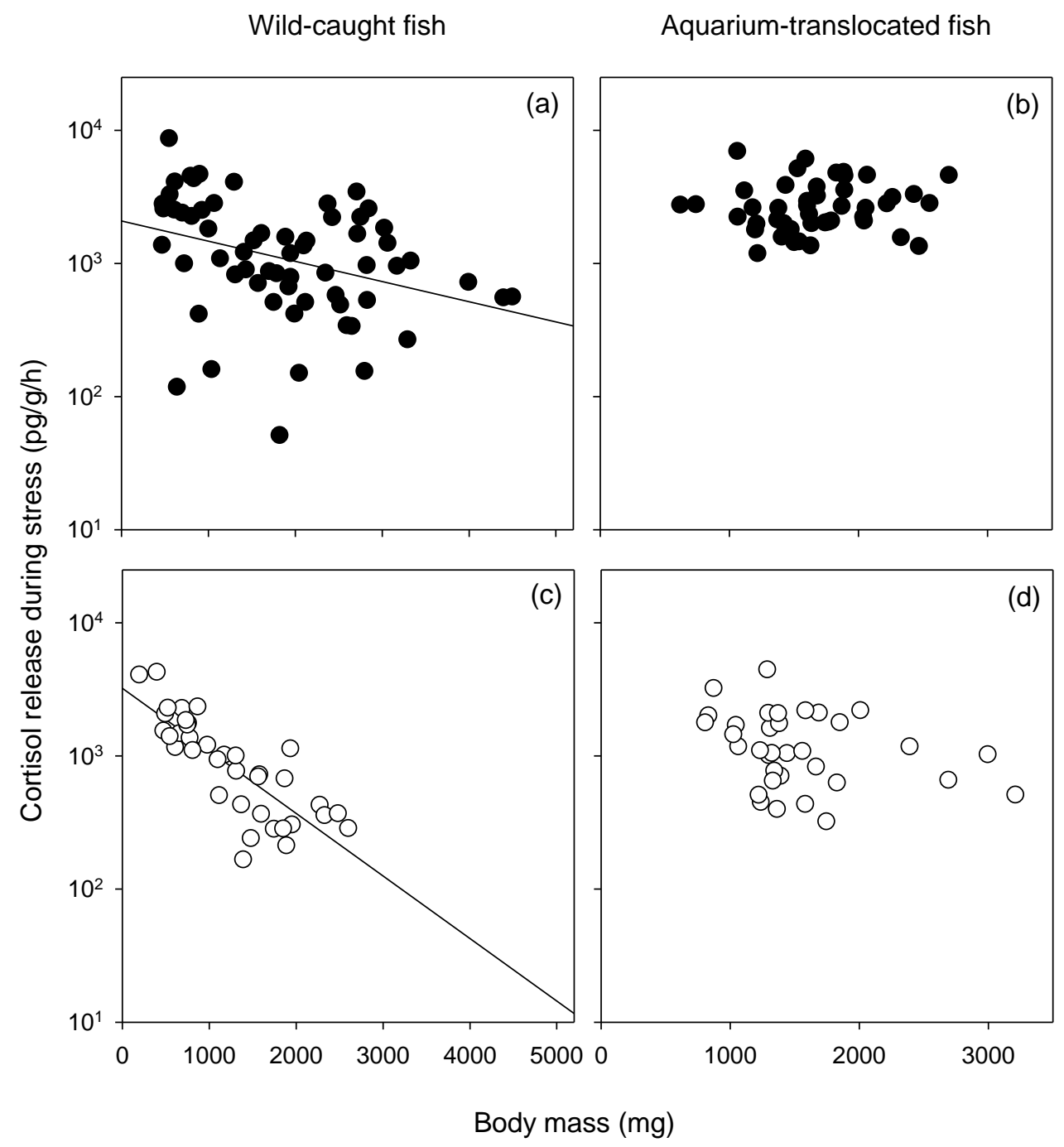

Figure 3. Scatter plots showing the relationship between body mass and the stress-induced release of cortisol to water for: (a) female $(O)$ and $(c)$ male $(O)$ sticklebacks captured in March 2014; and (b) female and (d) male fish captured at the same sites in October 2013 and measured in March 2014 after 5 months captivity. The best-fit linear regression lines are shown. Fig. 3a: $r 2=0.26, P<0.001, n=43$; Fig. 3b: $r 2=0.00, p=0.67, n=46$; Fig. 3c: $r 2$ $=0.57, P<0.001, n=37$; Fig. 3d: $r 2=0.08, p=0.1, n=34$. 


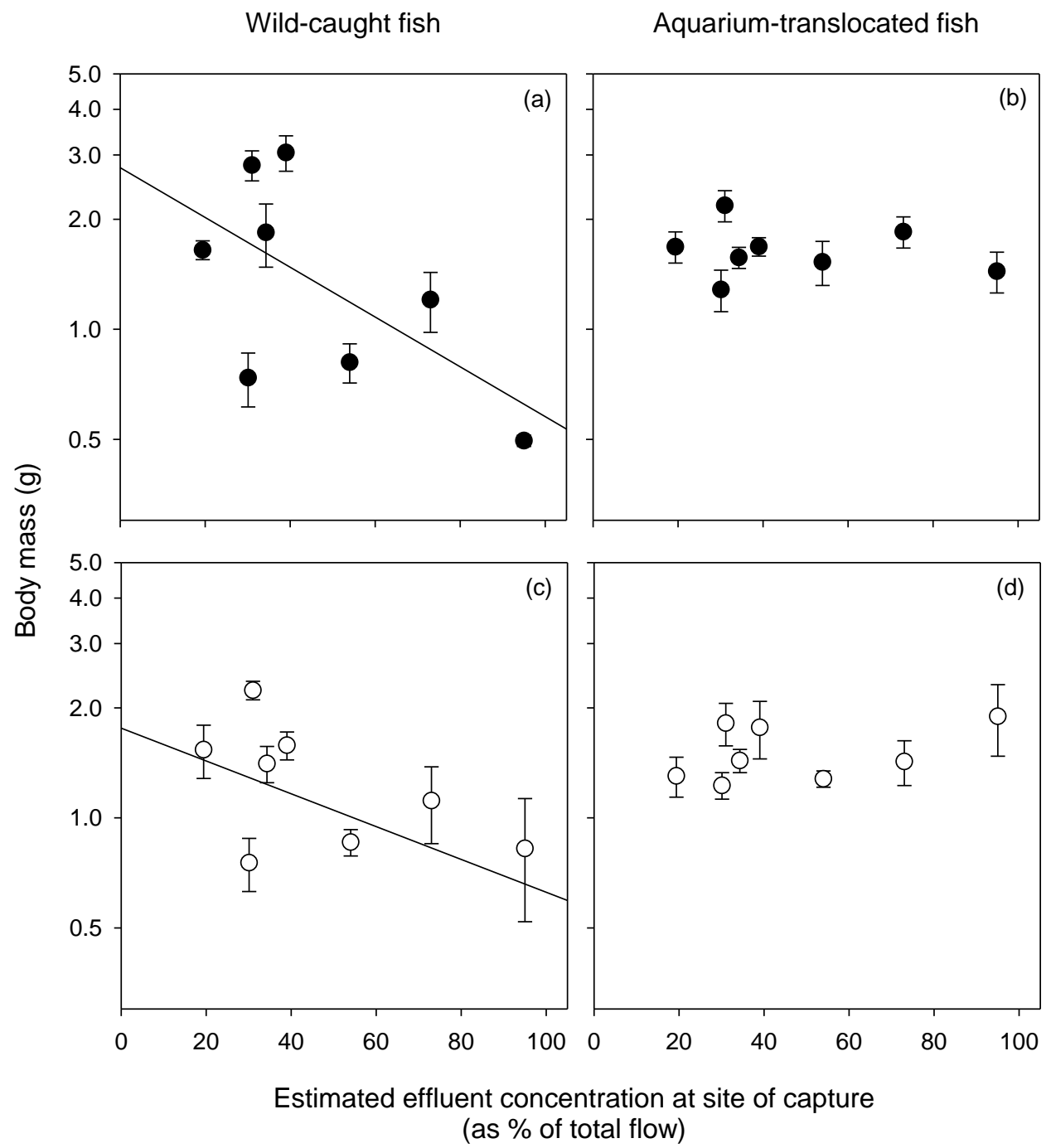

Figure 4. Scatter plots showing the relationship between the estimated effluent concentration (as \% of total river flow) at the capture sites and the body mass of: (a) female (O) and (c) male (O) sticklebacks captured in March 2014; and (b) female and (d) male fish captured at the same sites in October 2013 and measured in March 2014 after 5 months captivity. Best-fit regression lines are shown. The regressions were conducted using the raw data, but means \pm SEM are shown for clarity, $n=3-7$. Fig. 4a: $r 2=0.19, p=0.003, n=43$; Fig. $4 b: r 2=0.00, p=0.76, n=46$; Fig. $4 c: r 2=0.14, p=0.02, n=37$; Fig. $4 d: r 2=0.06, p=0.18, n$ $=34$. 